\title{
Site synthesis of bismuth nanoparticles for electrochemical determination of lead
}

\author{
Shijie Wu ${ }^{1}$, Wenjing $\mathrm{Lu}^{2}$, Qi Kang ${ }^{1}$, Dazhong Shen ${ }^{1}$, Dawei Pan ${ }^{2}$ \\ ${ }^{1}$ Key Laboratory in Molecular and Nano-Materials Probes of the Ministry of Education of China, College of Chemistry, \\ Chemical Engineering and Materials Science, Shandong Normal University, Jinan 250014, People's Republic of China \\ ${ }^{2}$ Key Laboratory of Coastal Zone Environmental Processes, Yantai Institute of Coastal Zone Research (YIC), Chinese Academy \\ of Sciences (CAS), Yantai Shandong 264003, People's Republic of China \\ E-mail:dwpan@yic.ac.an
}

Published in Micro \& Nano Letters; Received on 28th July 2012

A report is presented on a novel and effective route to synthesise bismuth nanoparticles (BiNPs) on the electrode surface, which was carried out by ion-exchange in Nafion film coated on the electrode surface and subsequent electrochemical reduction of $\mathrm{Bi}^{3+}$ ions to $\mathrm{BiNPs}$ on site. The properties of the resulting BiNPs modified electrode were investigated by scanning electron microscopy, an energy dispersive X-ray microanalyser and electrochemistry. Almost $10 \mathrm{~nm}$ BiNPs were decorated in the matrix of Nafion film and showed excellent electrochemical activity. The BiNPs modified electrode has been successfully used for determination of $\mathrm{Pb}^{2+}$ by anodic stripping voltammetry with a linear range of $1.0-90 \mathrm{nM}$. The detection limit is $0.3 \mathrm{nM}$ with $5 \mathrm{~min}$ accumulation. The practical application of this modified electrode was carried out for determination of $\mathrm{Pb}^{2+}$ in water samples and the results were consistent with those obtained by inductively coupled plasma-mass spectrometry.

1. Introduction: Determination of trace heavy metals is an important issue in both public health and environmental monitoring. As a typical heavy metal, lead $\left(\mathrm{Pb}^{2+}\right)$ is one of the most serious environmental contaminants $[1,2]$, which is highly toxic to the nervous, immune, reproductive and gastrointestinal systems of both humans and animals [3, 4]. Hence, the development of a highly sensitive method for determination of trace lead has received considerable attention. Many techniques have been developed for sensitive analyses of various heavy metal ions, including inductively coupled plasma mass spectrometry [5], X-ray fluorescence spectrophotometry [6] and atomic absorption spectrophotometry [7]. However, these methods generally require expensive instruments and time-consuming pretreatments [8].

Anodic stripping voltammetry (ASV) has been recognised as a powerful electrochemical technique for sensitive, rapid and realtime analyses of heavy metal ions [9-12]. Proper choice of the working electrode is crucial for successful application of the stripping operation. In the past decade, mercury hanging or dropping electrodes have been widely used for ASV because of their easy formation of amalgam with reduced metal, excellent reproducibility and easy surface renewal [13-15]. However, because of its serious toxicity, the use of mercury can cause severe environmental and health problems [16]. Since Wang et al. [15] introduced a new type of working electrode for voltammetric stripping analysis the bismuth film electrode (BiFE) - this now represents an attractive alternative to traditionally used mercury film electrodes. Similar to $\mathrm{Hg}, \mathrm{Bi}$ is capable of forming fused alloys with heavy metals [17], and exhibits high hydrogen overpotential [18]. In addition to the attractive electrochemical properties, $\mathrm{Bi}$ is more environmentally friendly and less toxic. However, various surfactants in real samples can be absorbed on the surface of BiFE, which will result in serious interference and bad performance.

To overcome the above weaknesses of the BiFE, it is necessary to develop Bi nanoparticles (BiNPs) modified electrodes with a larger electrochemical active surface area, which are directly applicable to trace metal analysis without a predeposition step of $\mathrm{Bi}$ in a Bi-containing solution. Moreover, sensor characteristics such as the sensitivity and detection limit of the BiNPs modified electrodes are superior to those of the BiFEs. In recent years, many studies have focused on finding methods to synthesise BiNPs, such as flame spraying [19], inert gas condensation [20], laser ablation in solution [21] and solution phase chemical methods [22, 23].

In this Letter, we present a novel and simple method to synthesise BiNPs. Nafion (NA), a well known non-cross-linked perfluorosulphonate cation-exchange polymer, was used as a soft template to fabricate BiNPs flexibly and conveniently. The formation of the BiNPs modified electrode consisted of ion-exchange in the ultrathin NA film and subsequent electrochemical reduction of $\mathrm{Bi}^{3+}$ ions in NA film to BiNPs on site. The morphology and size of the BiNPs modified electrode can be controlled by the thickness of the template film and ion-exchange conditions. The resulting BiNPs/NA modified electrode can be used for determination of heavy metals in real water samples.

\section{Experiment}

2.1. Reagents: NA ( $5 \mathrm{wt} \%$ solution in a mixture of lower alphatic alcohols and water) was obtained from Sigma Aldrich (USA), which was diluted to $1 \mathrm{wt} \%$ when used. $0.01 \mathrm{M} \mathrm{Bi}^{3+}$ solution was prepared by dissolving bismuth nitrate (Sinopharm Chemical Reagent Beijing Co. Ltd, China) in $1 \mathrm{wt} \% \mathrm{HNO}_{3}$. Stock solution of $0.01 \mathrm{M} \mathrm{Pb}^{2+}$ was prepared by dissolving lead nitrate (Sinopharm Chemical Reagent Beijing Co. Ltd, China) in deionised water, and then diluted to various concentrations of working solutions. The concentrations of these working solutions were calibrated by inductively coupled plasma-mass spectrometry. $0.1 \mathrm{M}$ acetate buffer solution ( $\mathrm{pH}$ 3.5) prepared with sodium acetate and acetic acid was used as the supporting buffer solution for $\mathrm{Pb}^{2+}$ determination. All other chemicals were analytical reagents and used without further purification.

2.2. Apparatus: All electrochemical experiments were carried out in a conventional three-electrode cell controlled by a CHI 660D Electrochemical Work Station (CH Instruments, Inc.). A modified glassy carbon electrode (GCE) with a diameter of $3 \mathrm{~mm}$ was used as the working electrode, with an $\mathrm{Ag} / \mathrm{AgCl}$ (saturated $\mathrm{KCl}$ ) electrode and a platinum foil served as the reference electrode and auxiliary electrode, respectively. The morphology and an elemental composition of the modified electrodes were characterised by scanning electron microscopy (SEM, Hitachi S-4800, Japan) and an energy dispersive X-ray microanalyser (EDS, HORIBA EX-350), respectively. Lake water and tap water samples were analysed by inductively coupled plasma-mass spectrometry (ICP-MS) with an ELAN DRC II inductive coupling plasma-mass spectrometer (Perkin Elmer Ltd, Hong Kong). All electrochemical experiments were carried out at room temperature and in a non-deoxygenating condition.

2.3. Preparation of BiNPs/NA/GCE and analytical procedure: The dispersed BiNPs on the electrode surface were synthesised in the 
following way. Firstly, the bare GCE was hand-polished with alumina, then rinsed with water in an ultrasonic bath and allowed to dry in air. Secondly, $4 \mu \mathrm{l}$ of $1 \%$ NA was dropped on the electrode surface and the solvents were left to evaporate with an infrared light for $10 \mathrm{~min}$ and left to cool to room temperature. Thirdly, the electrode was immersed in an aqueous solution of $0.01 \mathrm{M} \mathrm{Bi}\left(\mathrm{NO}_{3}\right)_{3}$ for about $3 \mathrm{~h}$, and then rinsed with some water to remove unbound materials. In this way, $\mathrm{Bi}^{3+}$ ions were exchanged into $\mathrm{NA}$ film. Finally, $\mathrm{Bi}^{3+}$ ions were reduced to form metallic BiNPs by an electrochemical reduction with the potential kept at $-0.6 \mathrm{~V}$ for $400 \mathrm{~s}$ in $0.5 \mathrm{M} \mathrm{H}_{3} \mathrm{BO}_{3}$ and $\mathrm{BiNPs} / \mathrm{NA} / \mathrm{GCE}$ was obtained.

The analysis of $\mathrm{Pb}^{2+}$ was performed in a $25 \mathrm{ml}$ beaker containing $0.1 \mathrm{M}$ acetate buffer ( $\mathrm{pH} 3.5$ ) without removal of oxygen. Quantitative determinations of $\mathrm{Pb}^{2+}$ were performed with differential normal pulse anodic stripping voltammetry (DNPASV). The parameters applied for DNPASV were as follows: accumulation potential, $-1.0 \mathrm{~V}$; accumulation time, $5 \mathrm{~min}$; equilibration time, $15 \mathrm{~s}$; increment, $0.004 \mathrm{~V}$; pulse amplitude, $0.05 \mathrm{~V}$.

\section{Results and discussion}

3.1. Characterisation of BiNPs: The NA film has interconnected ionic channels because of the outside of hydrophilic $\mathrm{SO}_{3}^{-}$. The swelled NA film after dipping in electrolyte ions will form much wider channels and thicker interconnected clusters because of ionexchange, which can act as a novel template for the formation of more nanoparticles of different dimensions instead of the nanorods formed in the homogeneous solution [24]. The BiNPs can be synthesised by the following reaction process with the above mechanism:

$$
\begin{gathered}
\mathrm{GCE}+\mathrm{NA}\left(\mathrm{SO}_{3} \mathrm{H}\right) \stackrel{\text { dipping }}{\longrightarrow} \mathrm{NA}\left(\mathrm{SO}_{3} \mathrm{H}\right) / \mathrm{GCE} \\
\mathrm{NA}\left(\mathrm{SO}_{3} \mathrm{H}\right) / \mathrm{GCE}+\mathrm{Bi}^{3+} \stackrel{\text { ion-exchange }}{\longrightarrow} \mathrm{NA}-\mathrm{Bi}^{3+} / \mathrm{GCE}+3 \mathrm{H}^{+} \\
\mathrm{NA}-\mathrm{Bi}^{3+} / \mathrm{GCE} \stackrel{\text { reduction }}{\longrightarrow} \mathrm{BiNP} / \mathrm{NA} / \mathrm{GCE}
\end{gathered}
$$

The SEM image of BiNPs on the electrode surface is shown in Fig. 1. It can be seen that the BiNPs with average diameter of $10 \mathrm{~nm}$ are randomly dispersed on the GCE surface. The BiNPs implanted into the NA film have moderate dispersion by using electrochemical reduction on site. The chemical compositions of NA film with BiNPs were further determined by energy dispersive $\mathrm{X}$-ray spectroscopy (EDS) and the result is shown in Fig. 2. In Fig. 2, C, O, F and $\mathrm{Bi}$ are the major elements. $\mathrm{C}, \mathrm{O}$ and $\mathrm{F}$ may come from the NA film. The peaks of element Bi existing in Fig. 2 indicate that BiNPs are actually immobilised in NA film.

Electrochemical behaviours of the bare GCE, NA/GCE and BiNPs/NA/GCE were studied in $0.5 \mathrm{M} \mathrm{H}_{2} \mathrm{SO}_{4}$ solution by linear

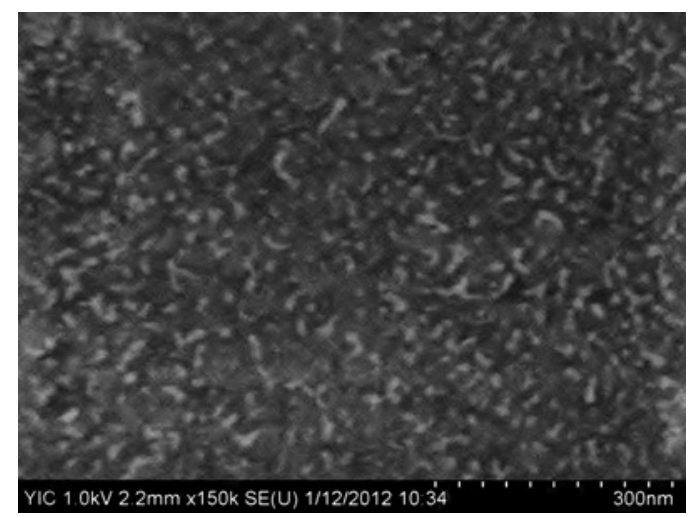

Figure 1 SEM image of BiNPS/NA/GCE

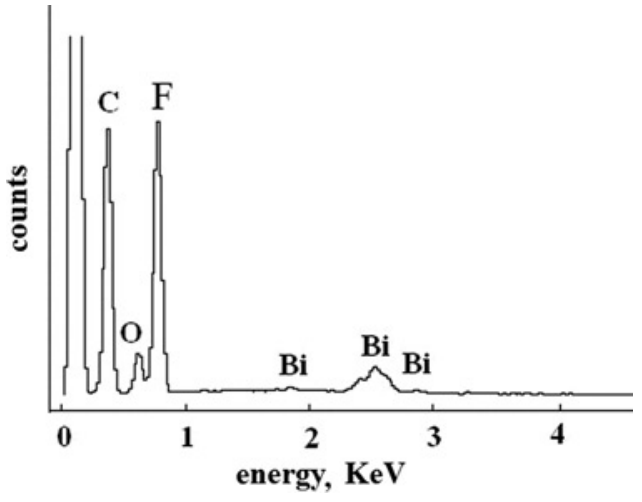

Figure 2 EDS pattern of BiNPS/NA/GCE

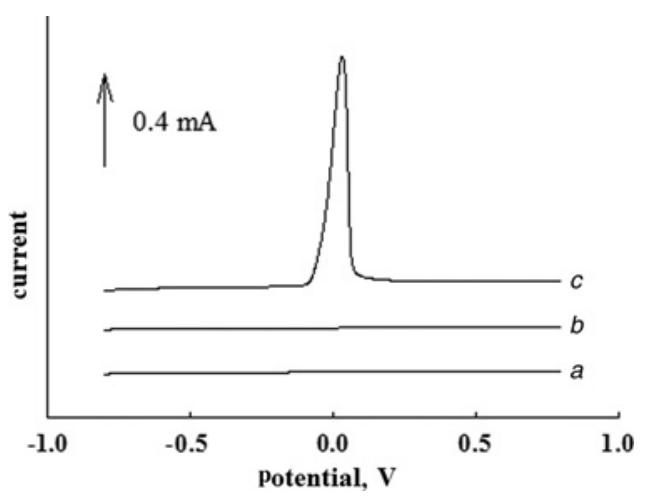

Figure 3 Linear sweeping voltammograms recorded at GCE, NA/GCE and BiNPS/NA/GCE bare

$a$ GCE

$b$ NA/GCE

c BiNPs/NA/GCE

Scan rate, $0.1 \mathrm{~V} / \mathrm{s}$

sweep voltammetry at a scan rate of $0.1 \mathrm{~V} / \mathrm{s}$. As shown in Fig. 3, the responses obtained at bare GCE (curve a) and NA/GCE (curve b) were almost a beeline, indicating no oxidation reaction occurs. However, a sharp oxidation peak at $0.032 \mathrm{~V}$ was observed at BiNPs/NA/GCE (curve c), which is because of the oxidisation of bismuth. The presented voltammetric behaviour of BiNPs/NA/ GCE demonstrates that BiNPs reduced on site in the matrix of the NA film still have excellent electrochemical activity. In addition, a wide available potential window can also be obtained at BiNPs/ NA/GCE, which implies the possibility of electrochemical detection of heavy metals in the appropriate potential region of the modified electrode.

3.2. Application of BiNPs/NA/GCE: To evaluate the ability of BiNPs/NA/GCE in electrochemical sensing applications, the detection of trace $\mathrm{Pb}^{2+}$ (as a model of heavy metals) was carried out at this modified electrode. The calibration curve for determination of $\mathrm{Pb}^{2+}$ at BiNPs/NA/GCE was established by using DNPASV and the corresponding results are shown in Fig. 4. For 5 min accumulation, a proportional relationship between the stripping peak current $\left(i_{\mathrm{p}}\right)$ and the concentration of $\mathrm{Pb}^{2+}$ was obtained in the range of 1.0 to $90 \mathrm{nM}\left(i_{\mathrm{p}}=-0.11+0.12 C, r=0.995, i_{\mathrm{p}}\right.$ in $\mu \mathrm{A}$, $C$ in nM) with a sensitivity of $0.12 \mu \mathrm{A} / \mathrm{nM}$. The detection limit given by the equation $C_{\mathrm{L}}=3 s_{b l} / S$ was calculated to be $0.3 \mathrm{nM}$, which is lower than that of the carbon paste electrode [25], the Hg-coated GCE [26], the polymer-coated Bi film electrode [27] and the Bi-modified carbon nanotube electrode [28] and so on. It can be proved that the resulting BiNPs/NA/GCE have a wider linear dynamic range, lower detection limit and larger sensitivity 


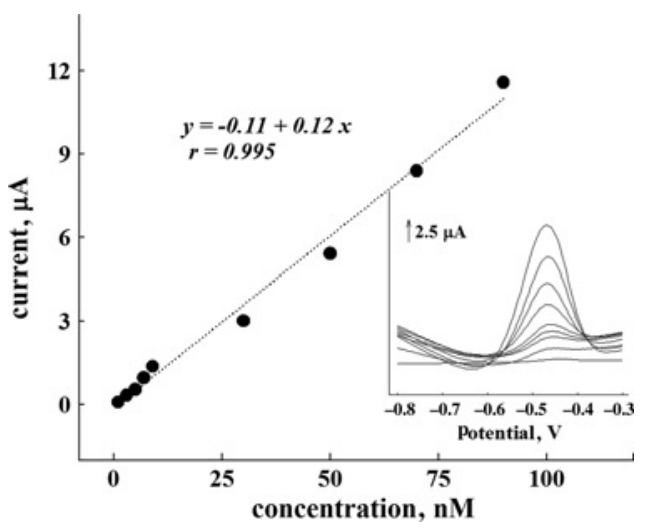

Figure 4 Calibration curve of $\mathrm{Pb}^{2+}$ at BiNPs/NA modified GCE Concentrations of $\mathrm{Pb}^{2+}$ for the inset curves are 1, 3, 5, 7, 9, 30, 50, 70 and $90 \mathrm{nM}$ from bottom to top, which are in the linear range

Accumulation potential, $-1.0 \mathrm{~V}$; accumulation time, $5 \mathrm{~min}$; equilibration time, $15 \mathrm{~s}$; increment, $0.004 \mathrm{~V}$; pulse amplitude, $0.05 \mathrm{~V}$

Table 1 Comparison of Bi-NPs/NA/GCE and ICP-MS for determination of $\mathrm{Pb}^{2+}$ in real water samples

\begin{tabular}{lcc}
\hline Sample & $\begin{array}{c}\text { Detected by } \\
\text { Bi-NPs/NA/GCE, } \mathrm{nM}^{\mathrm{a}}\end{array}$ & $\begin{array}{c}\text { Detected by } \\
\text { ICP-MS, nM }\end{array}$ \\
\hline lake water 1 & $23.7 \pm 0.15$ & 22.8 \\
lake water 2 & $9.71 \pm 0.41$ & 9.56 \\
lake water 3 & $8.74 \pm 0.28$ & 8.69 \\
tap water & $8.81 \pm 0.19$ & 8.83 \\
\hline
\end{tabular}

${ }^{\mathrm{a}}$ Average value of three determinations \pm standard deviation

than most of the other methods for voltammetric stripping determination of $\mathrm{Pb}^{2+}$. The response time of BiNPs/NA/GCE can be controlled within $5 \mathrm{~min}$. BiNPs/NA/GCE also have good reproducibility and repeatability. The relative standard deviations for $50 \mathrm{nM} \mathrm{Pb}^{2+}$ were found to be $3.8 \%$ for one electrode with three measurements and $5.3 \%$ for five electrodes with an accumulation time of $5 \mathrm{~min}$. The long-time stability of the proposed electrode in deionised water was performed in a supporting solution containing $50 \mathrm{nM} \mathrm{Pb}^{2+}$ on each day and the corresponding result shows that an almost $15 \%$ increase of the original current response to $\mathrm{Pb}^{2+}$ is observed in the first continuous three days.

The developed electrode was also applied for determination of trace $\mathrm{Pb}^{2+}$ in real water samples analysis. The contents of $\mathrm{Pb}^{2+}$ in the lake water and tap water samples were analysed using the standard addition method. To illustrate its accuracy in practical analysis, comparisons between BiNPs/NA/GCE and ICP-MS were illustrated. As shown in Table 1, the results obtained at BiNPs/NA/GCE are in accordance with those detected by ICPMS, which indicates that the resulting BiNPs/NA/GCE can be used directly for accurate analysis of $\mathrm{Pb}^{2+}$ in real water samples.

4. Conclusions: In this study, a novel, facile and effective method for the synthesis of BiNPs on the electrode surface was elaborated. Unique and well-dispersed BiNPs can be obtained by on site electrochemical reduction of $\mathrm{Bi}^{3+}$ ions trapped in the NA film with ionexchange. The resulting BiNPs/NA/GCE showed high sensitivity, good linearity, a low detection limit and wide linear range for determination of $\mathrm{Pb}^{2+}$. The practical determinations of $\mathrm{Pb}^{2+}$ in the lake water and tap water samples imply this kind of modified electrode has great potential application in heavy metal determination.

5. Acknowledgments: This work was financially supported by the National Natural Science Foundation of China (grant numbers
21007087 and 20975062), the Chinese Academy of Sciences (grant number KZCX2-YW-JS208), the Natural Science Foundation of Shandong Province (grant number BS2010HZ030), the Taishan Scholar Programme of Shandong Province and the Youth Innovation Promotion Association of CAS. The authors thank Dr. Wenhai Wang and Dr. Chengli Qu (Yantai Institute of Coastal Zone Research, Chinese Academy of Sciences, People's Republic of China) for providing the SEM image of BiNPs and ICP-MS testing, respectively.

\section{References}

[1] Xu H., Zeng L.P., Xing S.J., Xian Y.Z., Shi G.Y., Jin L.T.: 'Ultrasensitive voltammetric detection of trace lead(II) and cadmium(II) using MWCNTs-Nafion/bismuth composite electrodes', Electroanalysis, 2008, 20, pp. 2655-2662

[2] Huang S.S., Cheng Y.D., Li B.F., Liu G.D.: 'Simultaneous anodic stripping voltammetric determination of lead and cadmium with a carbon paste electrode modified by tributyl phosphate', Microchim. Acta, 1998, 130, pp. 97-101

[3] Kemper T., Sommer S.: 'Estimate of heavy metal contamination in soils after a mining accident using reflectance spectroscopy', Environ. Sci. Technol., 2002, 36, pp. $2742-2747$

[4] Jang A., Seo Y., Bishop P.L.: 'The removal of heavy metals in urban runoff by sorption on mulch', Environ. Pollut., 2005, 133, pp. 117-127

[5] Milne A., Landing W., Bizimis M., Morton P.: 'Determination of $\mathrm{Mn}, \mathrm{Fe}, \mathrm{Co}, \mathrm{Ni}, \mathrm{Cu}, \mathrm{Zn}, \mathrm{Cd}$ and $\mathrm{Pb}$ in seawater using high resolution magnetic sector inductively coupled mass spectrometry (HR-ICP-MS)', Anal. Chim. Acta, 2010, 665 , pp. 200-207

[6] Eksperiandova L.P., Blank A.B., Makarovskaya Y.N.: 'Analysis of waste water by $\mathrm{X}$-ray fluorescence spectrometry', X-Ray Spectrom., 2002, 31, pp. 259-263

[7] Jurado J.M., Martín M.J., Pablos F., ET AL.: 'Direct determination of copper, lead and cadmium in aniseed spirits by electrothermal atomic absorption spectrometry', Food Chem., 2007, 101, pp. 1296-1304

[8] Chapman P.J., Long Z., Datskos P.G., Archibald R., Sepaniak M.J.: 'Differentially ligand-functionalized microcantilever arrays for metal ion identification and sensing', Anal. Chem., 2007, 79, pp. 7062-7068

[9] Manisankar P., Vedhi C., Selvanathan G., Arumugam P.: 'Differential pulse stripping voltammetric determination of heavy metals simultaneously using new polymer modified glassy carbon electrodes', Microchim. Acta, 2008, 163, pp. 289-295

[10] Mandil A., Idrissi L., Amine A.: 'Stripping voltammetric determination of mercury(II) and lead(II) using screenprinted electrodes modified with gold films, and metal ion preconcentration with thiol-modified magnetic particles', Microchim. Acta, 2010, 170, pp. 299-305

[11] Nagaosa Y., Zong P., Kamio A.: 'Selenium-coated carbon electrode for anodic stripping voltammetric determination of copper(II)', Microchim. Acta, 2009, 167, pp. 241-246

[12] Morante-Zarcero S., Sánchez A., Fajardo M., Hierro I.d., Sierra I.: 'Voltammetric analysis of $\mathrm{Pb}(\mathrm{II})$ in natural waters using a carbon paste electrode modified with 5-mercapto-1methyltetrazol grafted on hexagonal mesoporous silica', Microchim. Acta, 2010, 169, pp. 57-64

[13] He X.H., Su Z.H., Xie Q.J., ET AL.: 'Differential pulse anodic stripping voltammetric determination of $\mathrm{Cd}$ and $\mathrm{Pb}$ at a bismuth glassy carbon electrode modified with Nafion, poly(2,5-dimercapto-1,3,4-thiadiazole) and multiwalled carbon nanotubes', Microchim. Acta, 2011, 173, pp. 95-102

[14] Nedeltcheva T., Atanassova M., Dimitrov J., Stanislavova L.: 'Determination of mobile form contents of $\mathrm{Zn}, \mathrm{Cd}, \mathrm{Pb}$ and $\mathrm{Cu}$ 
in soil extracts by combined stripping voltammetry', Anal. Chim. Acta, 2005, 528, pp. 143-146

[15] Wang J., Lu J., Hocevar S.B., Farias P.A.M.: 'Bismuth-coated carbon electrodes for anodic stripping voltammetry', Anal. Chem., 2000, 72, pp. 3218-3222

[16] Guzzi G.P., La Porta C.A.M.: 'Molecular mechanisms triggered by mercury', Toxicology, 2008, 244, pp. 1-12

[17] Long G.G., Freedman L.D., Doak G.O.: 'Bismuth and bismuth alloys, in: encyclopedia of chemical technology' (Wiley, New York, 1978), pp. 912-937

[18] Pauliukaite R., Hocevar S.B., Ogorevc B., Wang J.: 'Characterization and applications of a bismuth bulk electrode', Electroanalysis, 2004, 16, pp. 719-723

[19] Bonini M., Bardi U., Berti D., Neto C., Baglioni P.: 'A new way to prepare nanostructured materials: flame spraying of microemulsions', J. Phys. Chem. B, 2002, 106, pp. 6178-6183

[20] Andres R.P., Bielefeld J.D., Henderson J.I., ET $A L$. .: 'Selfassembly of a two-dimensional superlattice of molecularly linked metal clusters', Science, 1996, 273, pp. 1690-1693

[21] Mafune F., Kohno J.Y., Takeda Y., Kondow T.: 'Full physical preparation of size-selected gold nanoparticles in solution: laser ablation and laser-induced size control', J. Phys. Chem. B, 2002, 106, pp. 7575-7577

[22] Sun Y.G., Xia Y.N.: 'Shape-controlled synthesis of gold and silver nanoparticles’, Science, 2002, 298, pp. 2176-2179
[23] Yang C.S., Liu Q., Kauzlarich S.M., Phillips B.: 'Synthesis and characterization of $\mathrm{Sn} / \mathrm{R}, \mathrm{Sn} / \mathrm{Si}-\mathrm{R}$, and $\mathrm{Sn} / \mathrm{SiO}_{2}$ core/ shell nanoparticles', Chem. Mater., 2000, 12, pp. 983-988

[24] Xing S., Xu H., Chen J., Shi G., Jin L.: 'Nafion stabilized silver nanoparticles modified electrode and its application to Cr(VI) detection', J. Electroanal. Chem., 2011, 652, pp. $60-65$

[25] Beltagi A.M., Ghoneim E.M., Ghoneim M.M.: 'Simultaneous determination of cadmium (II), lead (II), copper (II) and mercury (II) by square-wave anodic stripping voltammetry at a montmorillonite-calcium modified carbon paste electrode', Int. J. Environ. Anal. Chem., 2011, 91, pp. 17-32

[26] McGaw E.A., Swain G.M.: 'A comparison of boron-doped diamond thin-film and Hg-coated glassy carbon electrodes for anodic stripping voltammetric determination of heavy metal ions in aqueous media', Anal. Chim. Acta, 2006, 575, pp. $180-189$

[27] Kefala G., Economou A.: 'Polymer-coated bismuth film electrodes for the determination of trace metals by sequential-injection analysis/anodic stripping voltammetry', Anal. Chim. Acta, 2006, 576, pp. 283-289

[28] Hwang G.H., Han W.K., Park J.S., Kang S.G.: 'Determination of trace metals by anodic stripping voltammetry using a bismuth-modified carbon nanotube electrode', Talanta, 2008, 76, pp. $301-308$ 